International Journal of Food Science, Nutrition and Dietetics (IJFS)

ISSN 2326-3350

\title{
Effect of Pomegranate (Punica granatum L.) Seed Oil on Markers of Oxidative Stress Induced by Carbon Tetrachloride in Wistar Rats
}

Melo ILP ${ }^{1 *}$, Silva $\mathrm{AMO}^{2}$, Carvalho EBT ${ }^{1}$, Yoshime $\mathrm{LT}^{1}$, Mancini $\mathrm{DAP}^{3}$, Mancini-Filho ${ }^{1}$

${ }^{1}$ Department of Food and Experimental Nutrition, São Paulo University, São Paulo, SP, Brazil.

${ }^{2}$ Biological Science and Health Center, Sergipe University, São Cristóvão, SE, Brazil.

${ }^{3}$ Virology Laboratory, Division of Scientific Development, Butantan Institute, São Paulo, SP, Brazil.

\section{Abstract}

\begin{abstract}
The pomegranate seed oil (PSO) presents a high content of the punicic acid (PA), which is a conjugated isomer of $\alpha$-linolenic acid (CLNA). Conjugated fatty acids have increasingly attracted scientific interest because of their several potential health benefits, including antioxidant activity. The aim of this study was to evaluate the supplementation effect of PSO on oxidative stress markers in rats subjected to liver injury by carbon tetrachloride $\left(\mathrm{CCl}_{4}\right)$. Animals were supplemented with PSO at concentrations of $2 \%$ and $4 \%$, for 21 days, and then subjected to liver injury induced by $\mathrm{CCl}_{4}$. The PSO supplementation reduced serum aminotransferase enzymes and the percentage of liver damage induced by $\mathrm{CCl}_{4}$. Conversely, PSO supplementation increased the lipid hydroperoxides levels in the liver. Overall, these results suggest that supplementation with PSO is not capable of attenuating markers of oxidative stress caused by $\mathrm{CCl}_{4}$.
\end{abstract}

Keywords: Conjugated Fatty Acid; Punicic Acid; Liver; Carbon Tetrachloride; Oxidative Stress.

\section{*Corresponding Author:}

Illana Louise Pereira de Melo,

Department of Food and Experimental Nutrition, Faculty of Pharmaceutical Sciences, São Paulo University; Av. Prof. Lineu Prestes, 580 Bloco 14, 05508-900, São Paulo, SP, Brazil.

Tel: 551130913688

Fax: 551138154410

E-mail: illanalpm@usp.br

Received: October 04, 2015

Accepted: October 28, 2015

Published: November 02, 2015

Citation: Melo ILP, et al., (2015) Effect of Pomegranate (Punica granatum L.) Seed Oil on Markers of Oxidative Stress Induced by Carbon Tetrachloride in Wistar Rats. Int J Food Sci Nutr Diet. S5:005, 1-8. doi: http:// dx.doi.org/10.19070/2326-3350-SI05001

Copyright: Melo ILP ${ }^{\circ}$ 2015. This is an open-access article distributed under the terms of the Creative Commons Attribution License, which permits unrestricted use, distribution and reproduction in any medium, provided the original author and source are credited.

\section{Introduction}

The pomegranate seed oil (PSO) has attracted attention in recent years due to the remarkable presence of a conjugated fatty acid, namely punicic acid (PA; C18:3-9c,11t,13c). PA is positional and geometric isomers of $\alpha$-linolenic acid, which presents three conjugated double bonds in its structure, in which one is in the trans position $[1,2]$. Several studies report that conjugated fatty acids (conjugated linoleic acids - CLAs and conjugated linolenic acids - CLNAs) display recognized anti-carcinogenic, antioxidant and anti-inflammatory properties, both in vitro and in vivo, and their effectiveness can vary substantially between individual isomers.
Saha e Ghosh (2012) showed that CLNAs ( $\alpha$-eleostearic acid and PA in a $0.5 \%$ dose of total lipids) significantly decreased oxidative stress by streptozotocin-induced diabetes in male albino rats; observed by reduction lipid peroxidation and antioxidant enzyme recovery [3-6].

The liver is an important organ in the bodies of vertebrates and is also the major site of metabolism of xenobiotics (drugs, toxins or alcohol). Some hepatotoxins including carbon tetrachloride $\left(\mathrm{CCl}_{4}\right)$, trigger liver injury and are characterized by different degrees of degeneration of hepatocytes and subsequent cell death. Some authors have already reported that the hepatotoxicity by $\mathrm{CCl}_{4}$ is an interesting experimental model to investigate liver damage induced by oxidative stress [7-10]. $\mathrm{CCl}_{4}$ is metabolized in the endoplasmic reticulum of hepatocytes by cytochrome P-450 NA$\mathrm{DH}$-dependent enzyme, generating highly reactive radicals such as trichloromethyl $\left(\mathrm{CCl}_{3}^{\bullet}\right)$ and trichloromethyl peroxyl $\left(\mathrm{CCl}_{3} \mathrm{O}_{2}^{\bullet}\right)$. Both are able to bind to proteins and cellular lipids, which is the initial step in the events cascade that lead to membrane lipid peroxidation and finally to cell death $[9,11,12]$. When the liver is in a stressed condition, that is, with a high level of $\mathrm{CCl}_{3}$, the oxidase xanthine activity increases with the progression of cell damage. This enzyme produces superoxide anions $\left(\mathrm{O}_{2}^{-}\right)$and hydrogen peroxide $\left(\mathrm{H}_{2} \mathrm{O}_{2}\right)$ [13]. There are three enzyme classes that are known to promote protection against this free radicals: superoxide dismutase (SOD), catalase (CAT) and glutathione peroxidase (GPx). SOD is an enzyme that converts the dismutation of $\mathrm{O}_{2}$ - into $\mathrm{H}_{2} \mathrm{O}_{2}$; CAT is a hemoprotein, which decomposes the $\mathrm{H}_{2} \mathrm{O}_{2}$ into oxygen and water, and GPx metabolizes $\mathrm{H}_{2} \mathrm{O}_{2}$ and hydroperoxides to nontoxic products. These enzymes can stop the chain reaction of lipid peroxidation in cell membranes and their activity is hindered by lipid peroxides and free radicals, thus reducing their enzymatic activity and increasing the toxicity induced 
by $\mathrm{CCl}_{4}[12]$.

Reactive oxygen species (ROS) studies and the development of new methods for evaluation of antioxidant activity have advanced considerably in recent years. The deleterious effect of ROS on cells and their association with certain diseases, acting as causative or aggravating agents, spurred the search for new substances capable of preventing or minimizing oxidative damage to cells [14]. According to the free radical theory, blocking or retarding the oxidation chain reaction is one of the most suitable strategies to prevent hepatotoxicity induced by oxidative stress [10]. In this sense, some studies have shown that oils rich in monounsaturated and polyunsaturated fatty acids provide hepatoprotective effects in rats and mice subjected to injury induced by $\mathrm{CCl}_{4}$, by elevating levels of endogenous antioxidant enzymes (SOD, CAT and GPx) and also by reducing the lipid peroxidation $[7,9,12,15]$.

Recently, Carvalho et al., [16] verified the effect of supplementation with an equimolar mixture of CLAs isomers (C18:2-9c11t and $\mathrm{C} 18: 2-10 t 12 c)$ in rats subjected to oxidative stress by $\mathrm{CCl}_{4}$. Authors observed a reduction in the lipid peroxidation rate and an increase in the CAT and glutathione reductase (GR) enzymes activities, regardless of the increase in reduced glutathione (GSH) in the liver of animals pretreated with CLAs. In this sense, taking into account that the CLNA contained in PSO is incorporated into rat liver in the form of CLAs, the aim of this study was to analyze whether the CLA obtained from PSO also enhanced the endogenous antioxidant defense system in rats subjected to $\mathrm{CCl}_{4}$.

\section{Materials and Methods}

\section{Sample}

The pomegranate seed oil (PSO) was obtained from the company Green Source Organics (Boynton Beach, USA). The product was produced by cold pressing the pomegranate seeds. The production of oil by using only cold pressing without further refining allows to preserve various valuable compounds. The principal fatty acids found of the oil (determined by GC) were: $6 \%$ C18:1-9c, 7\% C18:2-9c12c, 55\% C18:3-9c11t13c, 16\% C18:3-9c11t13t, 7\% C18:3-9t11t13c.

\section{Animals}

This study was approved by the Ethics Committee on Animal Experiments of the Faculty of Pharmaceutical Sciences (Protocol 281), University of São Paulo, Brazil. To evaluate the effect of PSO in vivo, 24 male Wistar rats, weighing between 120 and 150 grams (five weeks old), were used in the experiment. A balanced commercial diet (Nuvilab CR-1) and water were offered ad libitum. The animals were housed in polypropylene cages (three rats/cage) in an environment with controlled lighting (12 hours light/dark cycle) at $25^{\circ} \mathrm{C}$ and $60 \%$ humidity throughout the experimental period. The animals were distributed in four groups of six animals each, according to the initial weight (so that the average weight between the groups was similar):

- Negative control (-): rats treated with water.

- Positive control (+): rats treated with water and subjected to treatment with $\mathrm{CCl}_{4}$.

- CLNA 2\%: rats treated with 2\% PSO/CLNA (compared to the average daily consumption of diet), followed by treat- ment with $\mathrm{CCl}_{4}$.

- CLNA 4\%: rats treated with 4\% PSO/CLNA (compared to the average daily consumption of diet), followed by treatment with $\mathrm{CCl}_{4}$.

After a seven-day acclimatization period, the animals started receiving the PSO supplementation intragastrically using $3.0 \mathrm{~mL}$ disposable syringes and a gavage needle $(1.2 \mathrm{~mm}$ gauge, Insight Ltda). The experiment was conducted for 21 days and on days 19 and 21 , the animals were subjected to acute liver injury induced by $\mathrm{CCl}_{4}$ at a dose of $2 \mathrm{~mL} / \mathrm{kg}$ of mixture $\mathrm{CCl}_{4}$ : olive oil (1:1 dilution), intraperitoneal. The control (-) group (healthy rats) received an injection containing only the vehicle (olive oil). On day 22, after fasting for eight hours, the animals were anesthetized. Blood samples were collected by abdominal aorta artery and centrifuged at $3,500 \mathrm{rpm}$ for 15 minutes at $4^{\circ} \mathrm{C}$, the serum obtained was stored at $-80^{\circ} \mathrm{C}$ until analysis. The liver tissue was also collected, immediately frozen in liquid nitrogen and stored at $-80^{\circ} \mathrm{C}$ until analysis.

\section{Serum aminotransferases}

Alterations of biochemical markers of liver damage, that is, the levels of aspartate aminotransferase (AST) and alanine aminotransferase (ALT) were evaluated in triplicate using laboratory kits (Labtest ${ }^{\circledR}$, Lagoa Santa, Brazil). The results were expressed in units $(\mathrm{U})$ per deciliter $(\mathrm{dL})$.

\section{Liver fatty acids profile}

The lipids from liver tissue were extracted by the method described by Folch, Lees \& Sloane-Stanley [17]. The fatty acids were transformed into methyl esters in accordance with the method of alkaline esterification proposed by Christie, Dobson \& Adlof [18], using $\mathrm{NaOCH}_{3}$ in methanol. The extract was then injected into the gas chromatograph [GC-Shimadzu 2010 with flame ionization detector and fused silica $(100 \mathrm{~m}$ and $0.25 \mathrm{~mm}$ internal diameter/SP-2560) column] following the schedule described by Baublits et al., [19].

\section{Liver Morphometry}

A small piece of liver tissue of animals was collected and immediately fixed in formalin $(10 \%)$. Sections $(5 \mathrm{~mm})$ were prepared and stained with hematoxylin-eosin (HE) for photomicroscopic observations. The lesions observed in the liver parenchyma were analyzed by determining the mean percentage of injured area. Initially, were obtained five images of the same dimension, of each slide. The image acquisition was performed at 40x magnification (4x objective), the camera Cool SNAP-Procf (Media Cybernetics Inc., USA) was coupled to a microscope (Nikon Eclipse - E800, Japan). Then, the limits of lesions were set manually, the damaged areas per slide were summed and the mean lesion value was then obtained per group. The measurements were performed using the computerized imaging system Image - Pro Plus version 4.5 (Media Cybernetics Inc.). Results were expressed as mean \pm standard deviation.

\section{Liver homogenate and proteins quantification}

The liver tissue was weighed and homogenized with a potassium phosphate buffer $0.1 \mathrm{M}(\mathrm{pH} 7.0)$ at a proportion of $1: 3(\mathrm{~m} / \mathrm{v})$. The homogenates were centrifuged at $15,000 \mathrm{rpm}$ for 30 minutes at $4^{\circ} \mathrm{C}$ and the supernatants were used for the evaluation of lipid 
peroxidation and antioxidant enzyme activity.

The protein content in tissue homogenates was performed in triplicate by the method of Bradford [20], obtaining readings at a wavelength of $595 \mathrm{~nm}$ in a UV/Vis spectrophotometer (Spectronic $^{\circledR} 20$ Genesys $^{\mathrm{TM}}$, Rochester, USA). The amount of protein in the samples was calculated from the standard curve using bovine serum albumin (Sigma A4503).

\section{Lipid peroxidation and reduced glutathione contents}

The determination of lipid peroxidation in serum and liver homogenates was carried out by measuring the production of thiobarbituric acid reactive substances (TBARS) using the method described by Ohkawa, Ohishi \& Yagi [21] with minor adaptations. TBARS concentrations were calculated using a standard curve for $1,1^{\prime}, 3,3^{\prime}-($ TEP) tetraethoxypropane $(0,5-12 \mathrm{nMol})$ and were expressed as $\mathrm{nMol}$ of malondialdehyde (MDA) per milligram of protein.

The intracellular GSH content in the liver homogenate was quantified spectrophotometrically according to the method proposed by Tietze [22], which is based on the reaction of reduced glutathione (GSH) present in homogenates with 5,5'-dithiobis-2,2 nitrobenzoic acid (DTNB) that produces a colored compound that absorbs at $412 \mathrm{~nm}$. The concentration of GSH was quantified using a standard curve of GSH (of $50-800 \mu \mathrm{Mol} /$ Sigma G4251).

\section{Liver antioxidant enzymes activity}

The cytoplasmic superoxide dismutase (SOD) activity was evaluated according to the methods described by McCord \& Fridovich [23], using a reaction medium containing cytochrome $\mathrm{C}(100 \mathrm{mM})$, xanthine $(500 \mathrm{mM})$, ethylenediaminetetraacetic acid $(1 \mathrm{mM})$, potassium cyanide $(200 \mathrm{mM})$ and potassium phosphate buffer $(0.05$ $\mathrm{M}-\mathrm{pH}$ 7.8). The results were expressed as units per milligram of protein. One unit of SOD activity was defined as the amount of enzyme required to inhibit the reaction rate by $50 \%$ at $25^{\circ} \mathrm{C}$.

The catalase (CAT) activity was measured spectrophotometrically by calculating the rate of degradation of $\mathrm{H}_{2} \mathrm{O}_{2}$, the substrate of the enzyme at $37^{\circ} \mathrm{C}$ and $\mathrm{pH} 8.0$, according to the methods described by Beutler [24]. The results were expressed as units per milligram of protein. The unit of enzyme activity was defined as the amount of enzyme required to decomposed one $\mu \mathrm{Mol}$ of hydrogen peroxide per minute.

The glutathione peroxidase (GPx) activity in the liver homogenate was determined as described by Sies, Koch, Martino \& Boveris [25]. The results were expressed as units per milligram of protein. The unit of enzyme activity was defined as the amount of enzyme required to oxidize one $\mu \mathrm{Mol}$ of $\mathrm{NADPH}$ per minute at $30^{\circ} \mathrm{C}$ in $\mathrm{pH}$ 7.0.

The activity of glutathione reductase (GR) was determined according to the methodology described by Sies, Koch, Martino \& Boveris [25]. This method is based upon measuring the decrease in absorbance at $340 \mathrm{~nm}$ promoted by the oxidation of NADPH at $30^{\circ} \mathrm{C}$ for the reduction of oxidized glutathione (GSSG) catalyzed by GR. The reaction medium containing $50 \mathrm{mM}$ GSSG, NADPH (4 mM), $5 \mathrm{mM}$ EDTA and potassium phosphate buffer in $\mathrm{pH}$ 7.0. The results were expressed as units per $\mathrm{mg}$ of protein. One unit of the enzyme was defined as the enzyme activity that oxidizes one $\mu \mathrm{Mol}$ of NADPH per minute.

\section{Gene expression of SOD and CAT in liver}

Gene analysis of expression of SOD and CAT enzymes was performed by RT-PCR (reverse transcriptase-polymerase chain reaction) as described by Mancini-Filho, Vidal, Elsa \& González [26]. Initially, total RNA was obtained from liver tissue using Trizol reagent. Then, the phase of reverse transcription of RNA using reagents from Promega (Madison, AL, USA) was carried out as recommended by the manufacturer. The (cDNA) product was then amplified in a thermocycler. SOD was amplified at $94^{\circ} \mathrm{C}$ for $45 \mathrm{~s}, 56^{\circ} \mathrm{C}$ for $30 \mathrm{~s}$ and $72^{\circ} \mathrm{C}$ for $45 \mathrm{~s}$, for a total of 23 cycles followed by a 10 minutes time extension at $72^{\circ} \mathrm{C}$. CAT was amplified at $94^{\circ} \mathrm{C}$ for $30 \mathrm{~s}, 58^{\circ} \mathrm{C}$ for $30 \mathrm{~s}, 72^{\circ} \mathrm{C}$ for 1 minute for a total of 30 cycles for a time of 10 minutes extension at $72^{\circ} \mathrm{C}$. The amplified products were determined by electrophoresis on an agarose gel ( $2 \%$ ) containing $0.06 \mathrm{mg} / \mathrm{L}$ ethidium bromide. The gel was photographed on ultraviolet transillumination and quantified using Quantity One software (version 4.6.3 / Bio-Rad) and the results expressed as arbitrary units.

\section{Primer SOD - sequence (5'-3'): TCT AAG CAT GGC AAA GGT CC \\ Primer SOD - sequence (3'-5'): TTA CAG GCA GGC AT CAGCAG \\ Primer CAT - sequence (5'-3'): GCG AAT GGA GTG GAG GCA TAC \\ Primer CAT - sequence (3'-5'): GAG TGA CGT TGT CTT CAC CAT TAG TG}

\section{Statistical analysis}

Results were expressed as mean \pm standard deviation $(\mathrm{n}=3)$. Initially, the homogeneity of variances was checked by Hartley/Levene test and one-way analysis of variance (ANOVA) was applied to check for differences among groups (controls and PSO groups). Fisher LSD test was used to determine statistically significant differences in mean. When data were not normal, Kruskal-Wallis test was used in order to evaluate statistical differences among groups. Probability values ( $\mathrm{p}$-value) below 0.05 were considered statistically significant [27].

In order to detect associations between all results found to the rats included in the groups studied, Principal Component Analysis (PCA) was used to project the groups in the factor-place (PC1 vs PC2) based on the biochemical responses assessed in the study. In this study PCA were used to better visualize results obtained experimentally, since there are many variables involved in the response of groups. The PCA aims to reduce the dimensionality of the original data set, preserving the greatest amount of information (variance) as possible. For this purpose, experimental results were autoscaled using the $z$-score $[(\mu-\mathrm{X}) / \sigma]$ and PCA analysis was based on linear correlations in which variances were calculated as sums of squares/n-1 [28].

\section{Results and Discussion}

The PSO supplementation (CLNA groups) did not significantly alter weight gain of animals (Table 1). The levels of aminotransferases (Alanine - AST and Aspartate - ALT) and lipid peroxidation (TBARS) in serum, total lipids content, lipid peroxidation and reduced glutathione (GSH) in the liver of rats supplement- 
Table 1. Levels of aminotransferases, lipid peroxidation, total lipids content and reduced glutathione in the serum and liver of rats supplemented with pomegranate seed oil (CLNA group) for 21 days and submitted to liver injury with $\mathrm{CCl}_{4}$.

\begin{tabular}{|c|c|c|c|c|}
\hline Biochemistry parameters & Control (-) & Control (+) & CLNA 2\% & CLNA 4\% \\
\hline Weight gain & $156 \pm 32^{\mathrm{a}}$ & $156 \pm 18^{\mathrm{a}}$ & $154 \pm 15^{\mathrm{a}}$ & $154 \pm 21^{\mathrm{a}}$ \\
\hline Serum & & & & \\
Alanine aminotransferase (unit/mL) & $84 \pm 2.6^{\mathrm{c}}$ & $125 \pm 3.3^{\mathrm{a}}$ & $100 \pm 9.4^{\mathrm{b}}$ & $107 \pm 8.3^{\mathrm{b}}$ \\
Aspartate aminotransferase (unit/mL) & $53 \pm 2.0^{\mathrm{c}}$ & $97 \pm 15^{\mathrm{a}}$ & $67 \pm 8.3^{\mathrm{b}}$ & $77 \pm 17^{\mathrm{b}}$ \\
Lipid peroxidation (nMol MDA/mL) & $15 \pm 1.3^{\mathrm{a}}$ & $13 \pm 2.0^{\mathrm{a}}$ & $13 \pm 1.9^{\mathrm{a}}$ & $13 \pm 1.7^{\mathrm{a}}$ \\
\hline Liver & & & & \\
Total lipids content $(\%)$ & $3.3 \pm 0.2^{\mathrm{b}}$ & $3.9 \pm 0.5^{\mathrm{b}}$ & $3.7 \pm 1.3^{\mathrm{b}}$ & $5.4 \pm 1.6^{\mathrm{a}}$ \\
Lipid peroxidation (nMol MDA/mg protein) & $0.6 \pm 0.1^{\mathrm{c}}$ & $1.2 \pm 0.3^{\mathrm{b}}$ & $1.9 \pm 0.5^{\mathrm{a}}$ & $2.0 \pm 0.4^{\mathrm{a}}$ \\
Reduced glutathione $(\mu \mathrm{Mol} / \mathrm{mg}$ protein) & $176 \pm 41^{\mathrm{a}}$ & $410 \pm 71^{\mathrm{b}}$ & $251 \pm 22^{\mathrm{ac}}$ & $293 \pm 69^{\mathrm{c}}$ \\
\hline
\end{tabular}

$*$ Different letters indicate significant differences $(\mathrm{p}<0.05)$.

ed with pomegranate seed oil (CLNA groups) for 21 days and submitted to liver injury with $\mathrm{CCl}_{4}$ are shown in Table 1 . Rats subjected to liver injury with $\mathrm{CCl}_{4}$ presented an increase of aminotransferases as compared to the control (-). Rats treated with PSO had significantly reduced concentrations of AST and ALT when compared to the control $(+)$. However, the AST/ALT ratio did not differ between groups (Control (-): 1.58; Control (+): 1.29; CLNA 2\%: 1.49; CLNA 4\%: 1.39), indicating that hepatocellular injury can be considered light. According to Lee, Shih, Hsu \& Yen [10], it is well known that chemical compounds such as $\mathrm{CCl}_{4}$ cause liver injury, which increases AST and ALT in serum, and this may indicate the index of liver injury. In this sense, compared to other studies using $\mathrm{CCl}_{4}$, that showed very high levels of AST and ALT in $\mathrm{CCl}_{4}$ treated groups compared to healthy controls [10, 12, 15], the values presented here are lower and may indicate a mild liver injury. Still, it can be seen that the PSO treatment attenuates the increase of AST and ALT induced by $\mathrm{CCl}_{4}$.

Lipid peroxidation is considered a marker of oxidative damage [10]. According to Table 1, it can be seen that the method used for induction of hepatic injury did not result in severe liver damage. No significant differences were observed in serum TBARS values between control group and the group that presented liver injury. However, there was the control groups (control + was bigger). Regarding the groups treated with PSO, the TBARS values increased significantly compared to both controls (healthy and treated with $\mathrm{CCl}_{4}$ ).

Some authors have reported that animals subjected to injury with $\mathrm{CCl}_{4}$ and supplemented with oils rich in polyunsaturated fatty acids (PUFAs) present a significant improvement in the TBARS levels $[9,12,29]$. Herein, lipid peroxidation is a particular kind of reaction resulting from oxidative attack by reactive free radicals in the PUFAs side chains of the phospholipids on the membranes [15]. In this sense, Fang \& Lin [15] supplemented mice diets with corn oil and induced liver injury with $\mathrm{CCl}_{4}$ and found that corn oil, which is rich in PUFAs, markedly increased hepatic lipid peroxidation products induced by $\mathrm{CCl}_{4}$ and therefore did not improve the hepatic fibrosis. Results of the current study suggests that, the greatest amount of total lipid and the presence of conjugated fatty acid in the liver of treated animals with PSO can be more susceptible to the attack of radical produced by $\mathrm{CCl}_{4}$, increasing the TBARS levels. Kim et al., [30] analyzed the effects of supplementation of conjugated linoleic acid on lipid peroxidation in rat liver and their results also indicated that the levels of hepatic TBARS were significantly higher $(p<0.05)$ in groups sup- plemented with CLAs than the mean values in the control group. The TBARS is a secondary product of lipid peroxidation, indicating that the additional treatment of CLAs can cause a higher extent of lipid peroxidation and thus a more pronounced liver damage with supplementation in high doses.

With respect to reduced glutathione (GSH), the control (+) group presented a significantly higher content (Table 1), whereas PSO supplementation had similar mean values as compared to the group control (-). The reduction in GSH values could be related to the increase of TBARS in PSO treated groups, resulting in increased consumption of GSH.

The lipids of liver tissue were extracted and the fatty acid profile was assessed (Table 1). The supplementation with PSO 4\% resulted in an increase in lipid content of the liver. Santos-Zago et al., [31] showed that the levels of lipids in the liver of rats supplemented with CLAs did not differ significantly from the control group, but it can be observed that there was an increase of fat globules in the livers of animals supplemented with CLAs, as shown by tissue histopathology. The histological pattern of cell organelles was not changed.

The fatty acid profiles of liver tissue from animals supplemented with PSO confirmed the metabolism and tissue incorporation of CLAs (Table 2). Only traces of punicic acid in the livers of animals supplemented with PSO/CLNA were detected. However, CLAs $(9 c 11 t$ and $10 c 12 c)$ were present in a dose-dependent manner, corroborating other studies that claim that CLNAs are metabolized in the liver and incorporated as CLAs, mostly as C18:2$9 c 11 t$ [32-34]. Although some studies with CLAs report multiple health benefits $[35,36]$, there are also investigations regarding the possibility of adverse effects from the chronic and continued consumption of CLAs, particularly with regard to lipid accumulation in the liver and the increased risk of hepatic steatosis [37, 38].

In the current work, microscopic analysis showed that the liver tissue in the control (-) group was preserved, with hepatocytes presenting radial arrangement, and nuclei and cytoplasm were preserved. However, the groups treated with $\mathrm{CCl}_{4}$ exhibited evident morphological changes. The control $(+)$ group had micro and moderate macrogoticular vacuolar degeneration marked diffuse, and this observation was even more prominent around the central lobular vein. Large areas of coagulation necrosis associated with moderate neutrophilic infiltrate, cellular debris and hemorrhagic foci were clearly observed. On the groups treated with PSO, mild 
Table 2. Fatty acids (FAs) profile in liver of rats supplemented with pomegranate seed oil (CLNA group) for 21 days and subjected liver injury by $\mathrm{CCl}_{4}$.

\begin{tabular}{|c|c|c|c|c|c|}
\hline FAs & Control (-) & Control (+) & CLNA $2 \%$ & CLNA 4\% & P-value \\
\hline C 16:0 & $17.11 \pm 0.17^{\mathrm{b}}$ & $21.10 \pm 1.20^{\mathrm{a}}$ & $19.93 \pm 1.69^{\mathrm{a}}$ & $20.14 \pm 1.53^{\mathrm{a}}$ & $<0.01$ \\
\hline C 18:0 & $19.53 \pm 0.89^{\mathrm{a}}$ & $12.78 \pm 1.45^{c}$ & $15.67 \pm 3.21^{\mathrm{b}}$ & $13.78 \pm 2.53^{\mathrm{bc}}$ & $<0.01$ \\
\hline 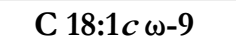 & $6.11 \pm 1.70^{c}$ & $14.00 \pm 3.47^{\mathrm{a}}$ & $10.81 \pm 3.34^{b}$ & $11.66 \pm 2.79^{\mathrm{ab}}$ & $<0.01$ \\
\hline 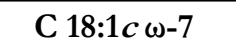 & $2.50 \pm 0.33$ & $2.36 \pm 0.26$ & & & 0.86 \\
\hline C 18:2c $\omega-6$ & $20.10 \pm 0.41^{\mathrm{c}}$ & $26.67 \pm 2.82^{\mathrm{a}}$ & $23.41 \pm 2.57^{b}$ & $23.38 \pm 1.88^{b}$ & $<0.01$ \\
\hline C $18: 3 c \omega-3$ & $0.73 \pm 0.23$ & $0.85 \pm 0.36$ & $0.70 \pm 0.17$ & $0.64 \pm 0.16$ & 0.54 \\
\hline CLA 9c11 $t$ & & & $2.97 \pm 0.72^{\mathrm{b}}$ & $6.35 \pm 1.13^{\mathrm{a}}$ & $<0.01$ \\
\hline CLA $10 c 12 c$ & & & $1.03 \pm 0.43$ & $1.59 \pm 0.53$ & 0.07 \\
\hline C 20:4 $\omega-6$ & $28.28 \pm 1.42^{\mathrm{a}}$ & $16.99 \pm 1.59^{\mathrm{b}}$ & $19.89 \pm 3.20^{\mathrm{b}}$ & $17.36 \pm 2.91^{\mathrm{b}}$ & $<0.01$ \\
\hline C $18: 39 c 11 t 3 c$ & & & $0.39 \pm 0.07^{\mathrm{b}}$ & $0.66 \pm 0.24^{a}$ & $<0.01$ \\
\hline C $22: 6 \omega-3$ & $5.65 \pm 0.49$ & $5.24 \pm 1.08$ & $5.19 \pm 1.14$ & $4.46 \pm 1.15$ & 0.3 \\
\hline
\end{tabular}

*Different letters in the same row differ statistically from each other, $\mathrm{p}<0.05$.

Figure 1. Values for percentage of damaged area of the liver of rats supplemented with pomegranate seed oil (CLNA group) for 21 days and subjected a liver injury with $\mathrm{CCl}_{4}(\mathrm{p}<0.01)$.

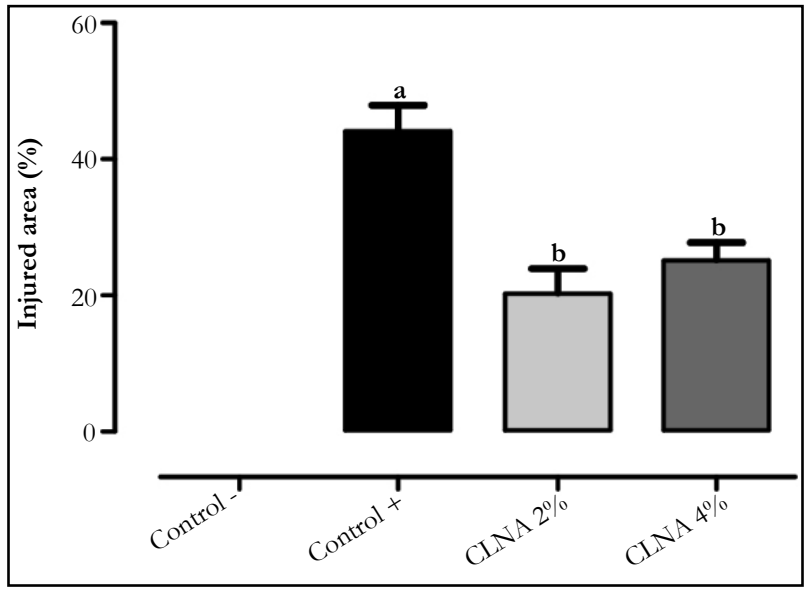

to moderate micro and macrogoticular vacuolar degeneration was attained, and this effect was more prominent around the lobular central vein and areas of coagulation necrosis were mainly located on the surface of the body associated with a mild neutrophilic infiltrate, cellular debris and foci of hemorrhage. The lesions observed in the liver parenchyma were analyzed by determining the mean percentage of injured area in order to quantify the differences between the control $(+)$ group and the group supplemented with PSO CLNA (Figure 1).

In Figure 1, it appears that the PSO supplementation (rich in punicic acid - CLNA) protected the liver parenchyma against the deleterious effects of $\mathrm{CCl}_{4}$, suggesting that CLAs incorporated into this tissue has a protective effect on hepatocytes against damage caused by free radicals. Photomicrographs representing the areas of lesions per group are shown in Figure 2.

The reactive oxygen species (ROS), such as anionic superoxide and hydrogen peroxide $\left(\mathrm{H}_{2} \mathrm{O}_{2}\right)$, are produced during normal cellular aerobic metabolism. The main component of the antioxidant system in mammalian cells is composed of three enzymes, namely superoxide dismutase (SOD), catalase (CAT) and glutathione peroxidase (GPx). These enzymes constitute a mutually supportive team of defense against ROS [16]. Oxidative stress plays a critical role in the pathophysiology of several liver diseases, and many complications of these diseases are mediated by oxidative stress, oxidative stress-related mediators, and inflammation. Oxidative stress in the liver is induced by numerous systemic diseases such as hypertension, diabetes mellitus, and hypercholesterolemia, as well as by some chemical agents such as antibiotics, chemotherapeutics, and radiocontrast. Environmental toxins, occupational chemicals, smoking, and alcohol consumption may also trigger oxidation in the human body, when the endogenous antioxidant defense system cannot counterbalance this condition [39].

The activity of the antioxidant enzymes (SOD, CAT, GPx and GR) in the liver of the tested groups is presented in Figure 3. A significant reduction of the CAT enzyme in the control (+) group induced by $\mathrm{CCl}_{4}$ was observed as compared to the control group (-), whereas the supplementation with PSO $4 \%$ increased the enzyme activity to values similar to that of the control (-) group. Conversely, no differences $(p>0.05)$ in the activity of SOD and glutathiones (GPx and GR) between the control groups were observed, suggesting again that the method of induction of hepatic injury with $\mathrm{CCl}_{4}$ was not strong enough to cause serious damage to the tissue to the point of altering the activity of these enzymes. However, there was a reduction in the activity of GPx in the group supplemented with PSO 4\%, suggesting that this enzyme may have been inactivated by lipid peroxides formed by lipid peroxidation. Similar results were observed in rats sup- 
plemented with CLAs and subjected to liver injury by $\mathrm{CCl}_{4}[16]$. The CLAs activity as antioxidants has been studied in recent years, but the results are contradictory and inconclusive [40]. Researchers examined the biological effects of a commercial mixture of isomers of CLAs in a model of fibrosis induced by $\mathrm{CCl}_{4}$ in rats and the CLAs significantly inhibited the increase of collagen fibers in the liver. These results indicate hepatoprotective effects of CLAs on liver fibrosis induced by $\mathrm{CCl}_{4}$ [41]. Carvalho et al., [16] also suggested that the supplementation with CLAs has a hepatoprotective effect in an experimental model in which rats are subjected to oxidative stress by $\mathrm{CCl}_{4}$ since the CLA reduced lipid peroxidation and increased the activity of CAT and GSH content.

Studies regarding the effects of CLNAs in animals subjected to oxidative stress are scarce. Sara \& Ghosh [42] analyzed the influence of two isomers of CLNA ( $0.5 \%$ of total lipids offered for 15 days) against oxidative stress induced by sodium arsenite, which is a generator of oxidative stress by increasing reactive oxygen species. The results showed that the sodium arsenite altered the activity of antioxidant enzymes in plasma and liver and brain homogenates. While the eleostearic acid ( $\alpha$-ESA C18:3-9c11t13t) and PA increased the activity of SOD, CAT and GPx and reduced the activity nitric oxide synthase (NOS) to normal values. Some dif- ferences in the effectiveness of the two isomers were observed, and this effect is attributed to their antagonistic cis-trans molecular arrangement. In this study, $\alpha$-ESA was more effective as an antioxidant than the PA due to its higher trans content. However, no dose-response effect was observed [43]. These authors also examined the effect of CLNAs under oxidative stress, reducing lipid peroxidation and restoring the activity of antioxidant enzymes in serum and pancreas of diabetic rats induced by streptozotocin [4].

The results of gene expression of SOD and CAT enzymes show that there were no changes on PSO group as compared with controls (Figure 4), indicating a direct action on the activity of these enzymes without altering expression of the gene. In order to detect associations between the results obtained in the current work, PCA was applied to autoscaled data, as shown in Figure 5.

According to Figure 5, it is possible to observe that the groups are arranged in quadrants separately, with a cumulative variance of $91.99 \%$, emphasizing the formation of groups with similar characteristics, according to the response variables selected. Supplementation with PSO is involved in the increase of total lipids and TBARS in the liver as well as with a reduction in the activity of SOD, GPx and GR, indicating that this oil had no positive ef-

Figure 2. Photomicrographs of histological sections of liver showing areas of injury. Groups: Control (-) (a), Control (+) (b), CLNA 2\% (c) and CLNA 4\% (d). Coloration: HE; increase: 4x; scale: $20 \mu \mathrm{m}$.
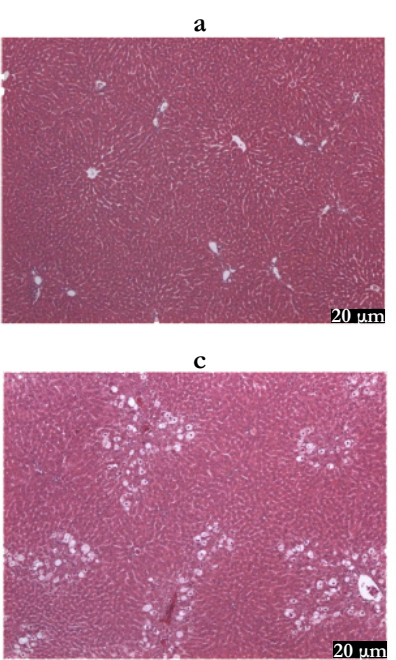

b

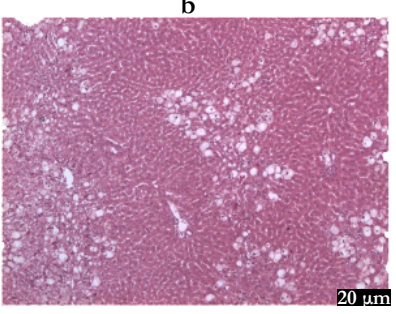

d

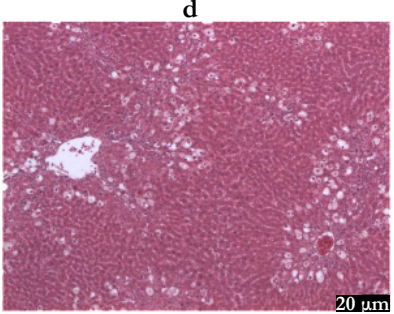

Figure 3. Antioxidant enzymes activity: superoxide dismutase $(\mathrm{a} / \mathrm{p}=0.02)$, catalase $(\mathrm{b} / \mathrm{p}=0.01)$, glutathione peroxidase $(\mathrm{c} / \mathrm{p}<0.01)$, and glutathione reductase $(\mathrm{d} / \mathrm{p}=0.52)$ in liver of rats supplemented with pomegranate seed oil (CLNA group) for 21 days and subjected a liver injury with $\mathrm{CCl}_{4}$.

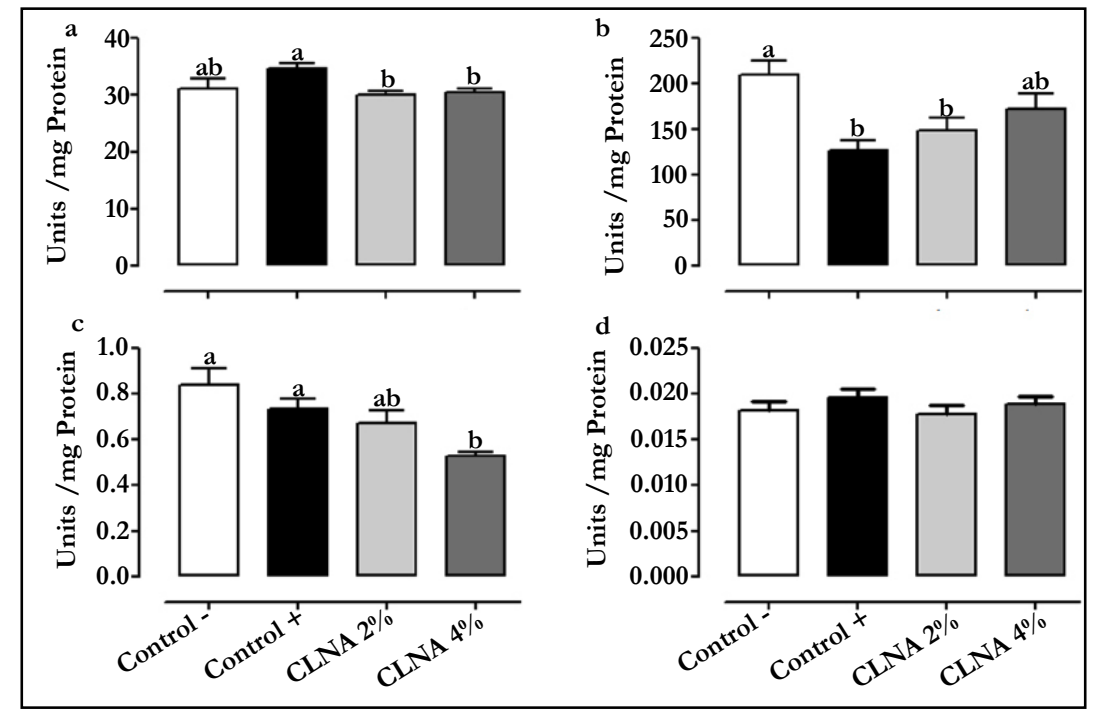


Figure 4. Gene expression of antioxidant enzymes: SOD (a) and CAT (b) in liver of rats supplemented with pomegranate seed oil (CLNA group) for 21 days and subjected a liver injury with $\mathrm{CCl}_{4}(\mathrm{p}>0.05)$.

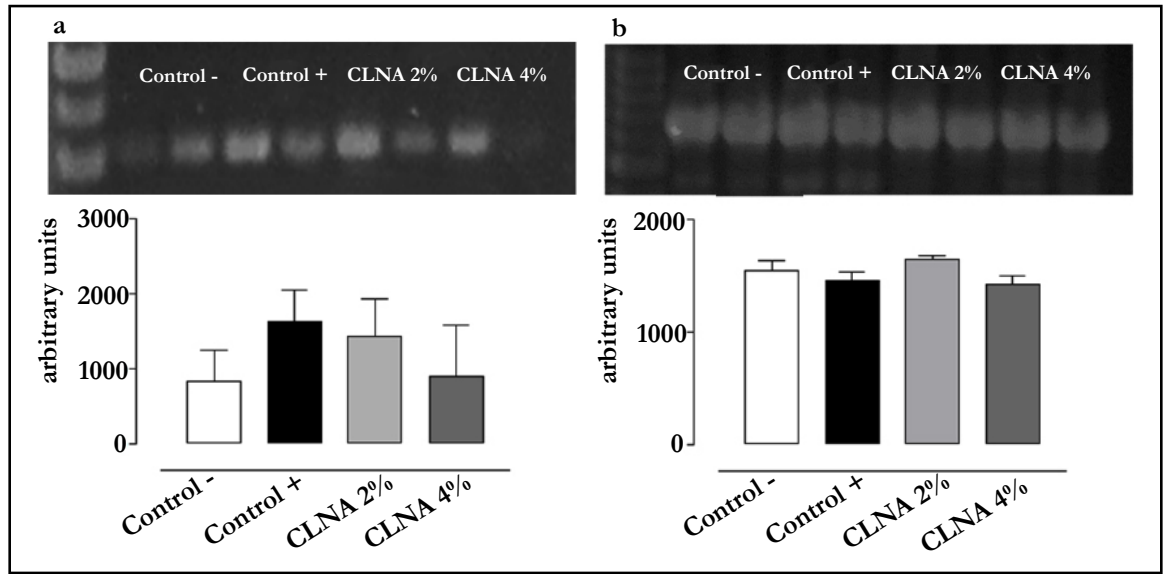

Figure 5. Principal Component Analysis (PC1 x PC2) to show differences in the evaluated parameters between the control groups and supplemented with pomegranate seed oil (CLNAs groups).

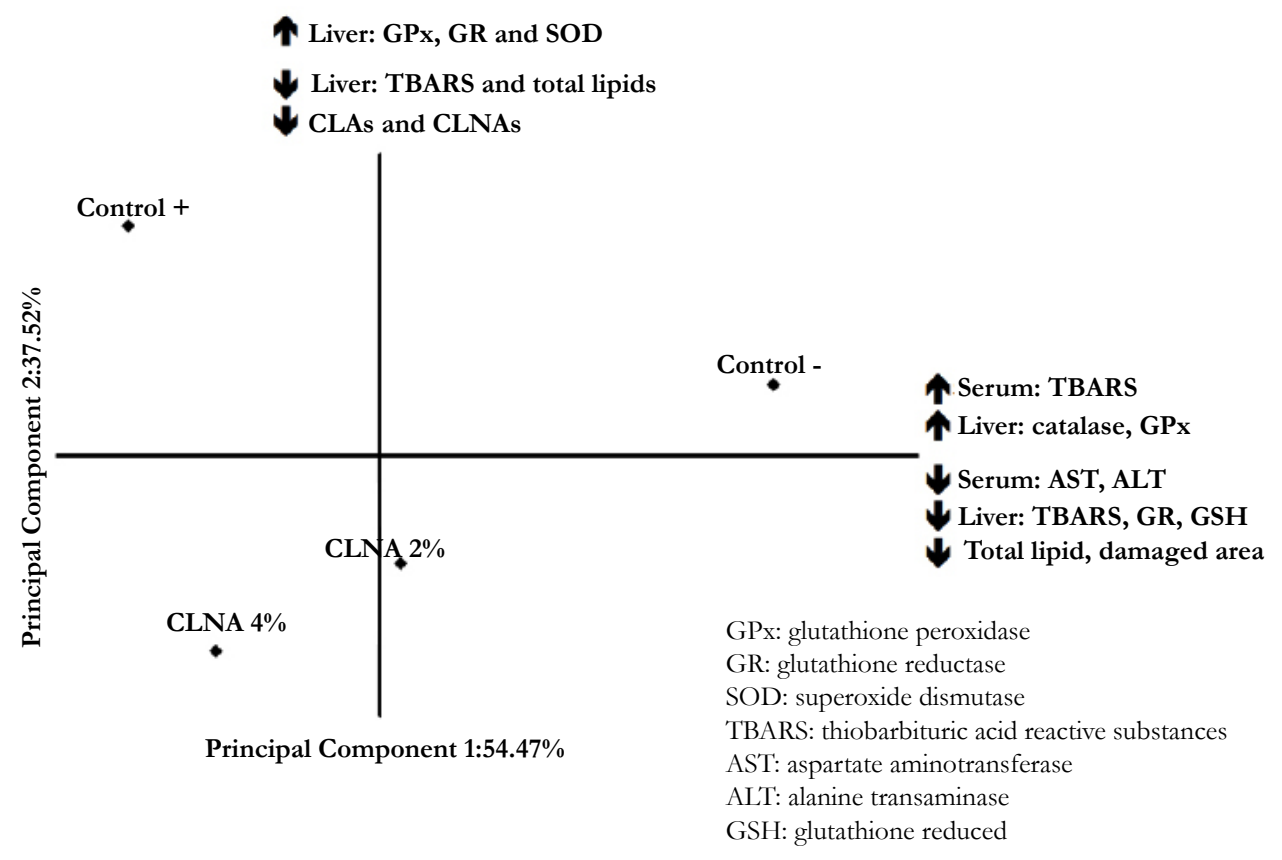

fects on markers of oxidative stress in this experimental model.

\section{Conclusion}

Considering the presented results, it is reasonable to conclude that rats supplemented with PSO presented reduced serum aminotransferase concentrations and liver damage caused by $\mathrm{CCl}_{4}$. However, PSO provided a substrate for the free radicals formation, increasing lipid hydroperoxide levels in the liver. The catalase activity was the most sensitive to the attack by $\mathrm{CCl}_{4}$, in which even with the damage caused by $\mathrm{CCl}_{4}$, PSO supplementation at a dose of $4 \%$ increased the catalase activity to normal levels. This effect was not related to the gene expression of this enzyme in liver tissue. SOD, GPx and GR enzymes were not changed, but GSH levels were reduced by supplementation with PSO and the mean value was close to that of the control (-). Overall, the results suggest that supplementation with PSO at $4 \%$ concentration is not able to attenuate the markers of acute oxidative stress caused by $\mathrm{CCl}_{4}$ in adults Wistar rats.

Additional studies using longer treatment and/or evaluating the effect of chronic oxidative stress conditions may be useful to investigate the action of pomegranate seed oil as an antioxidant.

\section{Acknowledgments}

The authors would like to thank National Council of Technological and Scientific Development (CNPq) and São Paulo State Research Foundation (FAPESP) which supported our research (Grants 09/51890-0; 09/51891-7 and 13/24490-7).

\section{References}

[1]. Melo ILP, Carvalho EBT de, Mancini-filho J (2014) Pomegranate Seed Oil ( Punica Granatum L .): A Source of Punicic Acid ( Conjugated $\alpha$-Linolenic Acid ). J Hum Nutr Food Sci 2: 1-11.

[2]. Vroegrijk IO, van Diepen JA, van den Berg S, Westbroek I, Keizer H, et al. (2011) Pomegranate seed oil, a rich source of punicic acid, prevents dietinduced obesity and insulin resistance in mice. Food Chem Toxicol 49(6): 1426-1430.

[3]. Verardo V, Garcia-Salas P, Baldi E, Segura-Carretero A, Fernandez-Gutierrez A, et al. (2014) Pomegranate seeds as a source of nutraceutical oil naturally rich in bioactive lipids. Food Res Int 65(Part C): 445-452.

[4]. Saha SS, Ghosh M (2012) Antioxidant and anti-inflammatory effect of conjugated linolenic acid isomers against streptozotocin-induced diabetes. $\mathrm{Br} \mathrm{J}$ Nutr 108(6): 974-983.

[5]. Hennessy AA, Ross RP, Devery R, Stanton C (2011) The health promoting properties of the conjugated isomers of $\alpha$-linolenic acid. Lipids 46(2): 
105-119.

[6]. Boussetta T, Raad H, Lettéron P, Gougerot-Pocidalo MA, Marie JC, et al. (2009) Punicic acid a conjugated linolenic acid inhibits TNF $\alpha$-induced neutrophil hyperactivation and protects from experimental colon inflammation in rats. PLoS ONE 4(7): e6458.

[7]. Shaaban AA, Shaker ME, Zalata KR, El-kashef HA, Ibrahim TM (2014) Modulation of carbon tetrachloride-induced hepatic oxidative stress, injury and fibrosis by olmesartan and omega-3. Chem Biol Interact 207: 81-91.

[8]. Yeh YH, Hsieh YL, Lee YT, Hu CC (2012) Protective effects of Geloina eros extract against carbon tetrachloride-induced hepatotoxicity in rats. Food Res Int 48(2): 551-558.

[9]. Jia XY, Zhang QA, Zhang ZQ, Wang Y, Yuan JF, et al. (2011) Hepatoprotective effects of almond oil against carbon tetrachloride induced liver injury in rats. Food Chem 125(2): 673-678.

[10]. Lee CP, Shih PH, Hsu CL, Yen GC (2007) Hepatoprotection of tea seed oil (Camellia oleifera Abel.) against CCl4-induced oxidative damage in rats. Food Chem Toxicol 45(6): 888-895.

[11]. Kan S, Cheung MWM, Zhou Y, Ho WS (2014) Effects of Boiling on Chlorogenic Acid and the Liver Protective Effects of Its Main Products Against $\mathrm{CCl}_{4}$-Induced Toxicity In Vitro. J Food Sci 79(2): C147-C154.

[12]. Hsu YW, Tsai CF, Chen WK, Lu FJ (2009) Protective effects of seabuckthorn (Hippophaerhamnoides L.) seed oil against carbon tetrachloride-induced hepatotoxicity in mice. Food Chem Toxicol 47(9): 2281-2288.

[13]. Fang HL, Lai JT, Lin WC (2008) Inhibitory effect of olive oil on fibrosis induced by carbon tetrachloride in rat liver. Clin Nutr 27(6): 900-907.

[14]. Alves CQ, David JM, David JP, Bahia MV, Aguiar RM (2010) Métodos para determinação de atividade antioxidante in vitro em substratos orgânicos. Quimica Nova 33(10): 2202-2210.

[15]. Fang HL, Lin WC (2008) Corn oil enhancing hepatic lipid peroxidation induced by $\mathrm{CCl} 4$ does not aggravate liver fibrosis in rats. Food Chem Toxicol 46(6): 2267-2273.

[16]. de Carvalho EBT, de Melo ILP, e Silva AMDO, Mancini DAP, ManciniFilho J (2014) Effect of Conjugated Linoleic Acid (CLA) in Rats Subjected to Damage Liver Induced by Carbon Tetrachloride. Journal of Modern Medicinal Chemistry 2: 32-42.

[17]. Folch J, Lees M, Sloane Stanley GH (1957) A simple method for the isolation and purification of total lipides from animal tissues. J Biol Chem 226(1): 497-509

[18]. Christie WW, Dobson G, Adlof RO (2007) A practical guide to the isolation, analysis and identification of conjugated linoleic acid. Lipids 42(12): 1073-1084.

[19]. Baublits RT, Pohlman FW, Brown AH, Johnson ZB, Proctor A, et al. (2007) Injection of conjugated linoleic acid into beef strip loins. Meat Sci 75(1): 84-93.

[20]. Bradford MM (1976) A rapid and sensitive method for the quantitation of microgram quantities of protein utilizing the principle of protein-dye binding. Anal Biochem 72: 248-254.

[21]. Ohkawa H, Ohishi N, Yagi K (1979) Assay for lipid peroxides in animal tissues by thiobarbituric acid reaction. Anal Biochem 95(2): 351-358.

[22]. Tietze F (1969) Enzymic method for quantitative determination of nanogram amounts of total and oxidized glutathione: applications to mammalian blood and other tissues. Anal Biochem 27(3): 502-522.

[23]. McCord JM, Fridovich I (1969) Superoxide dismutase. As enzyma function for erythrocuprein. J Biol Chem 244(22): 6049-6055.

[24]. Beutler E (1975) Red cell metabolism: a manual of biochemical methods. (2nd edtn), Grune \& Stration, New York, London. 89-90.

[25]. Sies H, Koch OR, Martino E, Boveris A (1980) Increased biliary glutathione disulfide (GSSG) release in chronically ethanol-treated rats. Adv Exp Med Biol 132(2): 619-625.

[26]. Mancini-Filho J, Novoa AV, González AE, de Andrade-Wartha ER, de O e Silva AM (2009) Free Phenolic Acids from the Seaweed Halimeda monile with Antioxidant Effect Protecting against Liver Injury. Z Naturforsch C 64(9-10): 657-663
[27]. Granato D, de Araújo Calado VM, Jarvis B (2014) Observations on the use of statistical methods in Food Science and Technology. Food Res Int 55: 137-149.

[28]. Zielinski AF, Haminiuk CWI, Nunes CA, Schnitzler E, Ruth SM Van, et al. (2014) Chemical Composition, Sensory Properties, Provenance and Bioactivity of Fruit Juices as Assessed by Chemometrics : A Critical Review and Guideline. Comprehensive Reviews in Food Science and Food Safety 13(3): 300-316.

[29]. Maheswari MU, Rao PGM (2005) Antihepatotoxic effect of grape seed oil in rat. Indian J Pharmacol 37(3): 179-182.

[30]. Kim HK, Kim S, Ahn J, Cho I, Yoon C, et al. (2005) Dietary conjugated linoleic acid reduces lipid peroxidation by increasing oxidative stability in rats. J Nutr Sci Vitaminol 51(1): 8-15.

[31]. Santos-Zago LF, Botelho AP, Oliveira AC De, Maróstica Junior MR (2011) Conjugated linoleic acid supplementation: lipid content and hepatic histology in healthy Wistar rats. Ciência e Tecnologia de Alimentos 31(1): 141-146.

[32]. Yang L, Cao Y, Chen JN, Chen ZY (2009) Oxidative stability of conjugated linolenic acids. J Agric Food Chem 57(10): 4212-4217.

[33]. Yuan GF, Sinclair AJ, Sun HY, Li D (2009) Fatty Acid Composition in Tissues of Mice Fed Diets Containing Conjugated Linolenic Acid and Conjugated Linoleic Acid. Journal of Food Lipids 16(2): 148-163.

[34]. Tsuzuki T, Kawakami Y, Abe R, Nakagawa K, Koba K, et al. (2006) Conjugated linolenic acid is slowly absorbed in rat intestine, but quickly converted to conjugated linoleic acid. J Nutr 136(8): 2153-2159.

[35]. Ali YM, Kadir AA, Ahmad Z, Yaakub H, Zakaria ZA, et al. (2012) Free radical scavenging activity of conjugated linoleic acid as single or mixed isomers. Pharm Biol 50(6): 712-719.

[36]. Obsen T, Faergeman NJ, Chung S, Marlinez K, Gobern S, et al. (2012) Trans-10, cis-12 conjugated linoleic acid decreases de novo lipid synthesis in human adipocytes. J Nutr Biochem 23(6): 580-590.

[37]. Vyas D, Kadegowda AK, Erdman RA (2012) Dietary conjugated linoleic acid and hepatic steatosis: Species-specific effects on liver and adipose lipid metabolism and gene expression. J Nutr Metab 2012: 932928.

[38]. Andreoli MF, Gonzalez MA, Martinelli MI, Mocchiutti NO, Bernal CA (2009) Effects of dietary conjugated linoleic acid at high-fat levels on triacylglycerol regulation in mice. Nutrition 25(4): 445-452.

[39]. Saha SS, Ghosh M (2013) Protective effect of conjugated linolenic acid isomers present in vegetable oils against arsenite-induced renal toxicity in rat model. Nutrition 29(6): 903-910.

[40]. Carvalho EBT, Melo ILP, Mancini-Filho J (2010) Chemical and physiological aspects of isomers of conjugated fatty acids. Food Science and Technology 30(2): 295-307.

[41]. Yun HS, Do SH, Jeong WI, Yang HJ, Yuan DW, et al. (2008) Cytotoxic effects of the conjugated linoleic acid isomers t10c12, c9t11-CLA and mixed form on rat hepatic stellate cells and CCl4-induced hepatic fibrosis. J Nutr Biochem 19(3): 175-183.

[42]. Saha SS, Ghosh M (2009) Comparative study of antioxidant activity of alpha-eleostearic acid and punicic acid against oxidative stress generated by sodium arsenite. Food Chem Toxicol 47(10): 2551-2556.

[43]. Saha SS, Ghosh M (2011) Antioxidant effect of vegetable oils containing conjugated linolenic acid isomers against induced tissue lipid peroxidation and inflammation in rat model. Chem Biol Interact 190(2-3): 109-120.

Special Issue on

"Plant and Animal Nutrition"

Theme Edited by:

Lord Abbey, Dalhousie University, Canada. E-mail: LAbbey@Dal.Ca 